\title{
Microbial Flora of Dacryocystitis and its Antibiogram
}

\author{
Mahwish Jawaid $^{1 *}$, Aruna Sunder ${ }^{2}$ and Pratibha ${ }^{2}$ \\ ${ }^{1}$ Department of Microbiology, Deccan College of Medical Sciences, \\ Hyderabad - 500095, Telangana, India \\ ${ }^{2}$ Department of Microbiology, Sarojini Devi Eye Hospital, Osmania Medical College, \\ Hyderabad - 500082, Telangana, India \\ *Corresponding author
}

A B S T R A C T

\section{Keywords}

Dacryocystitis, Staphylococcus, Pseudomonas,

Fungi,

Chloramphenicol.

\section{Article Info}

Accepted:

10 October 2017

Available Online:

10 December 2017
The most common infection of the lacrimal apparatus is dacryocystitis. The lacrimal excretory system is prone to infection and inflammation for various reasons. 126 samples from 108 cases (90 unilateral cases +18 bilateral cases) were collected from clinically diagnosed Dacryocystitis patients attending outpatient department of Sarojini Devi Eye Hospital, Hyderabad. Out of 126 samples $73.15 \%$ were culture positive, of which $63.88 \%$ were bacterial, $2.77 \%$ were fungal and $6.48 \%$ were mixed etiology (bacterial+fungal). Gram positive bacteria were predominant, Staphylococcus aureus $(34.21 \%)$ followed by Staphylococcus epidermidis (28.94\%). Among Gram negative bacilli Pseudomonas aeruginosa was predominant $(5.26 \%)$. Fungi were isolated in 10 cases of which Dematiaceous $(n=5)$ were predominant. Infection was more commonly seen in left eye. Rate of infection was higher in females (59.26\%). Higher incidence of infection was seen in the age group of less than 1 year and above 50 years. Gram positive cocci were most susceptible to chloramphenicol (90.9\%) and least susceptible to ofloxacin (45.4\%). Pseudomonas aeruginosa was equally sensitive to gatifloxacin and moxifloxacin and less sensitive to ceftazidime and gentamicin. The knowledge of bacteriology of dacryocystitis would contribute to the choice of effective antimicrobial agents and would help to reduce the unnecessary load of antimicrobial agents.

\section{Introduction}

Eye and vision are vital to human beings. Vision is not only conveyance of pictures but also access window to express one's own self to the world. Loss of vision or disease of the eye totally upsets the tranquility of one's life. Dacryocystitis is defined as an inflammation of the lacrimal sac, which usually occurs because of obstruction of the nasolacrimal duct. The obstruction may be an idiopathic inflammatory stenosis (primary acquired nasolacrimal duct obstruction) or may be secondary to trauma, infection, inflammation, neoplasm, or mechanical obstruction (secondary acquired lacrimal drainage obstruction). It is, however, noticeable that many patients tolerate LDO with epiphora for many years without clinical infection, representing simple stenosis of lacrimal duct (SSLD). Obstruction of the nasolacrimal duct from whatever source results in stasis with the accumulation of tears, desquamated cells, and mucoid secretions. This creates a fertile 
environment for secondary bacterial infection. In acute dacryocystitis, patients can experience severe morbidity and rarely mortality. Morbidity is related primarily to the lacrimal sac abscess and spread of the infection. Chronic dacryocystitis is rarely associated with severe morbidity unless caused by a systemic disease. The primary morbidity is associated with chronic lacrimation, matting, and conjunctival inflammation and infection. As many as 30\% of new born infants are believed to have closure of nasolacrimal duct at birth.(1) If not treated promptly and aggressively, newborn infants can experience orbital cellulitis (because the orbital septum is formed poorly in infants), brain abscess, meningitis, sepsis, and death. The treatment of LDO in adults is surgery, either external or endonasal dacryocystorhinostomy (DCR), or occasionally silicone intubation. Walland and Rose (2) reported a fivefold risk of soft tissue infection after open lacrimal surgery without systemic antibiotic prophylaxis. According to them, postoperative soft tissue infection represents a significant risk of failure in lacrimal surgery. Knowledge of the bacteriology of LDO contributes significantly to the choice of prophylactic antimicrobial agents. During the past 20 years, there have been only a few studies on the bacteriology of chronic dacryocystitis. According to them, coagulase-negative staphylococci (CoNS) and Staphylococcus aureus are the most frequently isolated organisms in lacrimal sac infection. Coagulase negative Staphylococci (CONS), previously dismissed as contaminants are now emerging as important potential pathogens with the increase in number of severely debilitated patients and increased use of implants in hospitals. More than 30 species of CONS are recognised but only a few are commonly incriminated in human infections. Multidrug resistant strains are common.(3) It was therefore planned to study the species distribution and antibiotic sensitivity pattern of CONS isolated from various clinical specimens. The purpose of this study was to identify the bacterial aetiology and to determine the in vitro antibacterial susceptibility and resistance of bacterial pathogens to commonly used antibacterial agents. In view of the above facts, the present study, Microbial study of dacryocystitis and its antibiogram was undertaken at a tertiary care centre, Sarojini Devi Eye Hospital, Hyderabad.

\section{Materials and Methods}

A total of 108 patients of all age groups, of either sex, attending the outpatient department of the Sarojini Devi Eye Hospital, clinically diagnosed as suffering from dacryocystitis by the opthalmologist, were included in the study. Patients who had used either antibiotic eye-drops or systemic antibiotics for atleast one week before their visit to the outpatient department were excluded.

\section{Specimen collection}

After cleaning with normal saline swab, pressure was applied on medial epicanthetic fold, the regurgitant pus or serosanguious fluid was collected by sterile swab. Two sterile cotton swabs moistened with physiological saline were used for collection of discharge from the lacrimal punctum, ensuring that the lid margin or conjunctiva was not touched.

\section{Specimen processing}

One swab was spread on two labeled slides to prepare smears. The direct smears so made and stained by Gram stain and $\mathrm{KOH}$ methodfor fungal elements. The second swab was used for inoculation into culture media like Brain Heart Infusion broth (BHI), Blood agar (BA), Mac Conkey (MA), Chocolate agar (CA). The inoculated media were incubated at 
$37^{\circ} \mathrm{C}$ for 24 to 48 hrs. CA plates were incubated at $37^{\circ} \mathrm{C}$ in the presence of $5-10 \%$ $\mathrm{CO}_{2}$ for 24 to $48 \mathrm{hrs}$.

A positive culture was defined as a growth of the same organisms on more than two solid phase media or confluent growth on one solid medium and smear results consistent with cultures. A standardized protocol was followed for each ocular specimen for the evaluation of significant microbiological features. In vitro susceptibility testing was performed by Kirby-Bauer disc diffusion method and interpreted using Clinical and Laboratory Standards Institute's serum standards.(4) The antibacterial agents (Himedia Laboratories Pvt. Ltd., Mumbai, India) used were amikacin $(30 \mu \mathrm{g} /$ disk $)$, tobramycin (10 $\mu \mathrm{g} /$ disk), gentamicin (10 $\mu \mathrm{g} /$ disk $)$, ceftazidime (30 $\mu \mathrm{g} /$ disk), ciprofloxacin (5 $\mu \mathrm{g} /$ disk), norfloxacin (10 $\mu \mathrm{g} /$ disk), ofloxacin (5 $\mu \mathrm{g} /$ disk), gatifloxacin (5 $\mu \mathrm{g} /$ disk), moxifloxacin (5 $\mu \mathrm{g} / \mathrm{disk})$, chloramphenicol (30 $\mu \mathrm{g} /$ disk) were consistently tested for their efficacy against standard American Type Culture Collection (ATCC) bacteria (Staphylococcus aureus ATCC 25923) as a general quality control laboratory procedure.

All the isolates were subjected to cefoxitin disc diffusion test using a cefoxitin (30 $\mu \mathrm{g} /$ disk). A $0.5 \mathrm{Mc}$ Farland standard suspension of the isolate was made and lawn culture was done on Mueller Hinton agar plate. Plates were incubated at $35^{\circ} \mathrm{C}$ for $18 \mathrm{hr}$ and zone diameters were measured. An inhibition zone diameter of $\leq 21 \mathrm{~mm}$ was reported as resistant and $\geq 22 \mathrm{~mm}$ was considered as sensitive.

\section{Identification of fungal ocular pathogens}

The fungal elements were observed in $10 \%$ $\mathrm{KOH}$ mount and Gram stain. The fungi were identified based upon the colony characters, such as texture, color, growth rate on obverse side of Sabouraud's dextrose agar slants and presence of pigment on the reverse side of colony and whether the pigment was localized or diffuse. A Lactophenol cotton blue mount was done for the microscopic features like mycelium, conidium relationship between hyphae and fruiting bodies. Slide culture in cornmeal agar was used for the observation of conidiogenesis of filamentous fungi. For yeast like fungi, Germ Tube Test (GTT), microscopic morphology on cornmeal agar and urease production were done.

\section{Results and Discussion}

The most common infection of the lacrimal apparatus is dacryocystitis. The lacrimal excretory system is prone to infection and inflammation for various reasons. This mucus membrane-lined tract is contagious with two surfaces (conjunctival and nasal mucosal) that are normally colonized with bacteria. The functional purpose of the lacrimal excretory system is to drain tears from the eye into the nasal cavity. Obstruction of the nasolacrimal duct from whatever source results in stasis with the accumulation of tears, desquamated cells, and mucoid secretions above the level of obstruction. This creates a fertile environment for secondary bacterial infection (5). The present study included one hundred and eight cases of clinically diagnosed dacryocystitis which were studied for microbial involvement, of which $79(73.15 \%)$ were culture positive and 29 (26.85\%) samples showed no growth (Table 1). This is in accordance with the studies of Chaudhary et al., 2010, which reported the incidence of $76.66 \%$ of culture positive cases and $23.34 \%$ of culture negative cases (6). Worldwide, chronic dacryocystitis has been reported to be much more common in females than males, female predominance with a 3:1 ratio (due to obliteration of lumen) was reported by Iliff, 1996 (5). In our study also, female predominance was seen with the incidence of 
$59.25 \%$ in females and $40.7 \%$ in males (Table 2). This is in accordance with Chaudhary et al., (2005), where study was predominated to female subjects $65.4 \%$ (7). In our study, the involvement of the eye was mainly unilateral $(83.3 \%)$, either the right or the left eye and there were also some bilateral $(16.7 \%)$ cases. This correlated well with the findings of Prakash et al., (2012), reported the same incidence of $90 \%$ in unilateral cases and $10 \%$ in bilateral cases (Table 4). (8) There was a relatively high incidence of the disease on the left side (45.37\%) as compared to the right side $(37.9 \%)$. This correlated well with the findings of Chaudhary M et al., 2010, reported left eye involvement in 56 patients(46.6\%).(6) In general, the disease had predilection to the left side, especially in females, because of their narrow bony canal. The nasolacrimal duct and the lacrimal fossa formed a greater angle on the right side than on the left side (9). Age wise distribution of culture positive cases in our study was predominantlly > 50 years $19(79.16 \%),<1$ year $23(71.87 \%), 1-2$ years $14(73.68 \%)$, this is in correlation with the studies of Chaudhary, Imtiaz et al., (2005) which reported highest incidence with average age of 50.5 years(7) (Table 3). Among <1year age group majority of cases were observed in 3-6 months of age $16(31.3 \%)$ and 8 (15.6\%) cases in 6-9 months age. Similar study conducted by Ffooks gave the highest incidence in 3-6 months age $44.4 \%$ followed by $0-6$ months $26.3 \%$.(10) The most common organisms cultured in our study were Staphylococcus species, accounting for $63.15 \%$ of the isolates. This percentage compares fairly well with the results of Thicker and Buffam, (11) Huber-Spitzy et al., (12) and Coden et al., (13) (their percentages being 73\%, 51\%, and $49 \%$ respectively. Among Staphylococcus species isolated, predominant were Staphylococcus aureus (34.21\%), Staphylococcus epidermidis (28.94\%), This result compares fairly with the results of Prakash R.et al., 2012 identified Staphylococcus aureus in 26 (27.65\%) cases.(8) Staphylococcus aureus isolates among the total bacterial isolates (including pure bacterial and mixed isolates) of dacrocystitis cases in our study accounted to $34.21 \%$. All of them were subjected to MRSA screening using Cefoxitin disc diffusion test as it is in concordance with the PCR for mecA gene as shown by studies of Anand KB, P Agrawal et al., in 2009. (14) No MRSA was isolated in our study. Shanmuganathan et al., in 2005 concluded that MRSA was yet an infrequent cause of external occular infections. (15) In our study 4 cases of Staphylococcus hominis and 2 cases of Staphylococcus caprae was also isolated.

As stated in the studies of Mahajan and Alexander et al., (1980), Micrococci are increasingly accepted as human pathogens in ocular infections (16). Our study reported 5 (6.5\%) strains of Micrococci from the dacryocystitis cases both in the direct Gram stain from the sample and also isolation of Micrococci in culture. Bharathi et al., (2008), (17) reported Micrococci isolates in the 11 case of dacryocystitis, which were in accordance with our study. In our study 6 cases $(7.5 \%)$ of Streptococcus species were isolated, which correlated well with the study of Bharathi et al., (2007), who reported 8.6\% of Steptococci species (17). In our study 4 cases of Enterococci were also isolated, which is till now not reported by any other studies. Gram negative organisms represented $9.2 \%$ of the isolates of the total material in this study, the most frequently isolated species being Pseudomonas aeruginosa $(5.26 \%)$. This is in correlation with studies of Coden et al., who observed Gram negative organisms in $27 \%$ of all isolates, including Pseudomonas aeruginosa in 9\% (13). Among the Gram-negative organisms, Pseudomonas aeruginosa (16.6\%) was the most common reported by Kundu et al., (2008). (18) 
Table.1 Distribution of culture positive cases

\begin{tabular}{|c|c|c|c|c|}
\hline No. of cases studied & \multicolumn{2}{|c|}{ No. of positive cases } & \multicolumn{2}{c|}{ No. of negative cases } \\
\hline 108 & 79 & $73.15 \%$ & 29 & $26.85 \%$ \\
\hline
\end{tabular}

Table. 2 Gender distribution of patients and percentage of positive samples

\begin{tabular}{|c|c|c|}
\hline Gender & No. of collected samples (\%) & Organisms isolates (\%) \\
\hline Female & $64(59.25)$ & $49(76.56)$ \\
\hline Male & $44(40.7)$ & $30(68.18)$ \\
\hline Total & 108 & $79(73.15)$ \\
\hline
\end{tabular}

Table.3 Age wise distribution of culture positive cases

\begin{tabular}{|c|c|c|c|c|c|c|}
\hline Serial & Age group in & \multicolumn{2}{|c|}{ Sex group } & No. Of cases & No. Of & Percentage \\
\cline { 3 - 4 } No. & years & Male & Female & studied & positive cases & \\
\hline 1 & $<1$ & 12 & 20 & 32 & 23 & 71.87 \\
\hline 2 & $1-3$ & 11 & 08 & 19 & 14 & 73.68 \\
\hline 3 & $4-15$ & 06 & 05 & 11 & 08 & 72.72 \\
\hline 4 & $16-30$ & 04 & 06 & 10 & 07 & 70.00 \\
\hline 5 & $31-50$ & 03 & 09 & 12 & 08 & 66.66 \\
\hline 6 & $>50$ & 09 & 15 & 24 & 19 & 79.16 \\
\hline
\end{tabular}

Table.4 Growth pattern in unilateral and bilateral cases

\begin{tabular}{|c|l|c|c|c|}
\hline Serial No. & \multicolumn{1}{|c|}{ Infected eye } & Total & Growth & Growth \% \\
\hline 1 & Left eye & 49 & 38 & 77.55 \\
\hline 2 & Right eye & 41 & 29 & 70.73 \\
\hline 3 & Both eye & 18 & 12 & 66.66 \\
\hline & Total & 108 & 79 & 73.15 \\
\hline
\end{tabular}

Table.5 Different isolates recovered among the dacryocystitis cases

\begin{tabular}{|l|c|c|}
\hline \multicolumn{1}{|c|}{ Type of isolate } & Number & Percentage \\
\hline Bacterial isolates & 69 & 63.88 \\
\hline Fungal isolates & 03 & 02.77 \\
\hline Bacterial and fungal isolates & 07 & 06.48 \\
\hline Culture sterile & 29 & 26.85 \\
\hline Total & 108 & 100 \\
\hline
\end{tabular}


Table.6 Distribution of different isolates

\begin{tabular}{|l|c|c|}
\hline \multicolumn{1}{|c|}{ Name of species } & Number & Percentage \\
\hline Staphylococcus aureus & 26 & 34.21 \\
\hline Staphylococcus epidermidis & 22 & 28.94 \\
\hline Staphylococcus hominis & 04 & 05.26 \\
\hline Staphylococcus caprae & 02 & 02.63 \\
\hline Streptococcus species & 06 & 07.89 \\
\hline Enterococcus feacalis & 04 & 05.26 \\
\hline Micrococcus luteus & 05 & 06.57 \\
\hline Pseudomonas aeruginosa & 04 & 05.26 \\
\hline Acinetobacter baumanii & 02 & 02.63 \\
\hline Acinetobacter junii & 01 & 01.31 \\
\hline Dematiaceous fungi (unidentified) & 03 & 30 \\
\hline Candida species & 02 & 20 \\
\hline Aspergillus flavus & 02 & 20 \\
\hline Aspergillus fumigates & 01 & 10 \\
\hline Bipolaris species & 01 & 10 \\
\hline Curvalaria species & 01 & 10 \\
\hline
\end{tabular}

Table.7 Distribution of mixed bacterial and fungal isolates

\begin{tabular}{|l|c|c|}
\hline \multicolumn{1}{|c|}{ Organisms } & Number of cases & Percentage \\
\hline Staphylococcus epidermidis + Aspergillus species & 03 & 42.86 \\
\hline Staphylococcus aureus + Candida & 02 & 28.57 \\
\hline Staphylococcus epidermidis + Dematiaceous fungi & 02 & 28.57 \\
\hline Total & 07 & 100 \\
\hline
\end{tabular}

Table.8 Antimicrobial susceptibility pattern of various bacterial isolates

\begin{tabular}{|c|c|c|c|c|c|c|c|c|c|}
\hline Antibiotic & 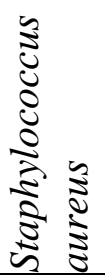 & 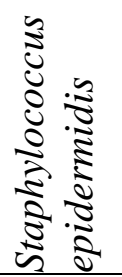 & 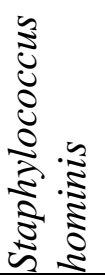 & 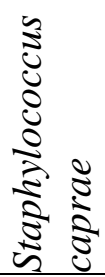 & 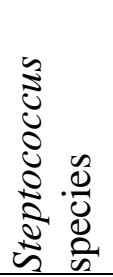 & 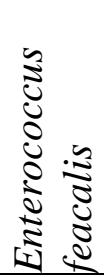 & 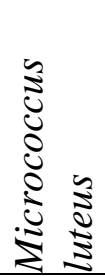 & 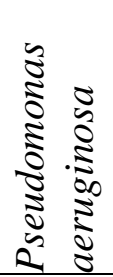 & 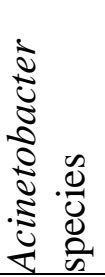 \\
\hline & $\mathrm{S} \%$ & $\mathrm{~S} \%$ & $\mathrm{~S} \%$ & $\mathrm{~S} \%$ & $\mathrm{~S} \%$ & $\mathrm{~S} \%$ & $\mathrm{~S} \%$ & S\% & $\mathrm{S} \%$ \\
\hline Ciprofloxacin & 54.5 & 42.8 & 75 & 50 & 100 & 25 & 60 & 50 & 100 \\
\hline Ofloxacin & 45.4 & 57.1 & 100 & 50 & 100 & 25 & 80 & 75 & 100 \\
\hline Gatifloxacin & 81.8 & 85.7 & 100 & 100 & 100 & 50 & 100 & 100 & 100 \\
\hline Moxifloxacin & 81.8 & 100 & 100 & 100 & 100 & 50 & 100 & 100 & 100 \\
\hline Chloramphenicol & 90.9 & 85.7 & 100 & 100 & 100 & 75 & 100 & - & - \\
\hline Ceftazidime & 27.2 & 14.2 & 75 & 50 & 100 & - & 100 & 50 & 33.3 \\
\hline Gentamicin & 81.8 & 71.4 & 100 & 50 & 100 & - & 80 & 50 & 100 \\
\hline robram & 90.9 & 85.7 & 100 & 100 & 0 & - & 100 & 100 & 100 \\
\hline
\end{tabular}


Acinetobacter species (2 A. baumanii complex and $1 A$. junii) was isolated in 3(4\%) cases of total isolates in our study, which correlates well with the studies of Prakash $\mathrm{R}$ et al., 2012 which reported $5.35 \%$ of nonfermenting Gram negative bacilli (8). In our study $10(9.25 \%)$ cases of fungi were isolated, 5 cases of Dematiaceous fungi (3 unidentified, 1 Curvalaria species and 1 Bipolaris species), 2 cases of Candida species, 2 cases of Aspergillus flavus and 1 Aspergillus fumigatus on par with observations of Brook Freizer et al., (1998), reported 2 cases of Candida albicans (19). In our study, among 10 (9.25\%) cases, $2.77 \%$ cases yielded pure fungal isolates and $6.48 \%$ were mixed bacterial and fungal growths with Staphylococcus species being the predominant bacterial isolate and Aspergillus species fungal isolate followed by Candida albicans and Dematiaceous fungi (Table 5, 6 and 7). In our study, most of the gram positive cocci were susceptible to chloramphenicol, and were equally susceptible to moxifloxacin and gatifloxacin. This is in correlation with the studies of Kebede et al., (2010), who reported the antibiotics to which the majority of the isolates sensitive to were chloramphenicol (82.4\%), gentamycin (79.1\%) (20). Among Gram negative organisms most of them are susceptible to chloramphenicol, gatifloxacin and tobramycin. Bharathi et al., (2010), reported all Gram positive cocci was most frequent isolated from ocular infections and were most sensitive to moxifloxacin and Gram negative were most sensitive to amikacin and gatifloxacin (17). Majority of the isolated organisms were least sensitive to ciprofloxacin and ofloxacin (Table 8).

During the past 20 years, there have been only a few studies on the bacteriology of Dacryocystitis. According to them Staphylococcus aureus was the most frequently isolated organisms in lacrimal sac infection. Coagulase negative Staphylococci (CONS), previously dismissed as contaminants are now emerging as important potential pathogens with the increase in number of severely debilitated patients and increased use of implants in hospitals. The changing pattern of bacterial flora and antibiotic sensitivity even in the same area and institution necessitates careful individual culture and sensitivity of every Dacryocystitis case. Knowledge of the bacteriology of LDO contributes significantly to the choice of prophylactic antimicrobial agent.

\section{References}

1. Khurana AK. Opthalmology. $3^{\text {rd }}$ edition. New Delhi: New Age International Publishers; 2003. Chapter 15, Lacrimal Apparatus; 342-6.

2. Walland MJ, Rose GE. Soft tissue infections after open lacrimal surgery. Ophthalmology 1994 Mar; 101(3): 60811.

3. Geary C, Jordens JZ, Richardson JF, Howcraft DM, Mitchell CJ. Epidermiological typing of Coagulase negative staphylococci from nosocomial infections. J Med Microbiol 1997; 46:195-203.

4. Clinical and Laboratory Standards Institute. Performance Standards for Antimicrobial Susceptibility Testing; seventeenth informational supplement. 19th ed, Vol. 1. Performance Standards for Antimicrobial Disk Susceptibility Tests: CLSI document 100-S17. M2A9. Approved Standard; 2007. p.27

5. Iliff NT. Infections of the lacrimal drainage system. In: Peopse JS, Holland GN, Wilhelmus KR (eds). Ocular Infection and Immunity. Mosby: $\mathrm{St}$ Louis, MO, 1996, p 1346-55.

6. Chaudhary M, Bhattarai A, Adhikari SK, Bhatta DR. Bacteriology and antimicrobial susceptibility of adult 
chronic dacryocystitis Nep J Oph 2010; 2(4): 105-113.

7. Chaudhry IA, Shamsi FA, Al-Rashed W. Bacteriology of chronic dacryocystitis in a tertiary eye care center. Ophthal Plast Reconstr Surg. 2005 May; 21(3): 207-10

8. Prakash R., Girish Babu R.J., Nagaraj E.R., Prashanth H.V., Jayashree S. Shah Journal of Clinical and Diagnostic Research. 2012 May (Suppl-2), Vol6(4): 652-655

9. Gilliland G. Dacryocystitis. In: Agarwal S, Agarwal A, Apple DJ, Buratto L, Alio JL, Pandey SK, Agarwal A, editors. Textbook of Ophthalmology. 1st ed. New Delhi: Jaypee brothers Medical Publishers (P) Ltd, 2002; 705-12

10. O. O. Ffooks Dacryocystitis in Infancy, Br J Ophthalmol 1962 46: 422-434

11. Thicker JA, Buffam FV. Lacrimal sac, conjunctival, and nasal culture results in dacryocystorhinostomy patients. Ophthal Plast Reconstr Surg.1993; 9: 43-6

12. Huber-Spitzy V, Steinkogler FJ, Huber E, Arocker-Mettinger E, Schiffbänker M. Acquired dacryocystitis: microbiology and conservative therapy. Acta Ophthalmol (Copenh) 1992; 70:745-9.

13. Coden DJ, Hornblass A, Haas BD. Clinical bacteriology of dacryocystitis in adults. Ophthal Plast Reconstr Surg 1993; 9: 125-31.
14. Anand KB, Agarwal P, Kumar S, Kapila K, comparison of cefoxitin disc diffusion test, oxacillin screen agar, and PCR for mecA gene for detection of MRSA. Indian J Med Microbiol. 2009; 27: 27-9.

15. Shanmuganathan VA, Armstrong M, Buller A, Tullo AB. External ocular infections due to methicillin-resistant Staphylococcus aureus (MRSA). Eye. 2005; 19: 284-291.

16. Mahajan VM, Alexander TA, Jain RK, Agarwal LP. Role of coagulase negative staphylococci and Micrococci in occular diseases. J Clin Pathol. 1980; 33(12): 1169-73.

17. Bharathi MJ, Ramakrishnan R, Maneksha V, Shivakumar C, Nithya V, Mittal S (2008). Comparative bacteriology of acute and chronic dacryocystitis. Journal of Aravind Eye Care System; (8): 20-28

18. Kundu PK, Mandal R, Banerjee AR, Biswas MC, Mondal A, Sasmal NK. A clinicobacteriological study of chronic dacryocystitis in adults. $J$ Indian Med Assoc. 2008; 106(5):296-98

19. Brook I, Fraizier EH. The aerobic and anaerobic microbiology of dacryocystitis. Am J Opthalmol. 1998; 125(4):552-4

20. Kebede A, Adamu Y, Bejiga A. Bacteriological study of dacryocystitis among patients attending in Menelik II Hospital, Addis Ababa, Ethiopia. Ethiop Med J. 2010 Jan; 48(1): 29-33.

\section{How to cite this article:}

Mahwish Jawaid, Aruna Sunder and Pratibha. 2017. Microbial Flora of Dacryocystitis and its Antibiogram. Int.J.Curr.Microbiol.App.Sci. 6(12): 1013-1020. doi: https://doi.org/10.20546/ijcmas.2017.612.113 